\title{
MONARQUÍA Y VIRTUD: ESTUDIO ICONOGRÁFICO DEL FRESCO DE LA BÓVEDA DE LA CÁMARA DE LA REINA MARGARITA DE AUSTRIA EN EL PALACIO DE EL PARDO
}

\author{
POR \\ ARACELI MARTÍNEZ MARTÍNEZ \\ Escuela de Arte. Madrid
}

Si Felipe II en 1560 decidió para las estancias privadas del palacio de El Pardo una decoración rica y
ensual, en 1607, el nuevo programa que, tras el incendio de 1604, aprobó Felipe III se ciñe a la metáfora de
católica corte adornada con todas las virtudes, teologales y cardinales. La intención del programa decora-
vo de esta bóveda parece explícita: la Monarquía española, personificada en la Reina, madre del heredero,
nuncia un amanecer nuevo y feliz. La excelencia de la virtud como atributo de la Reina y, sobre todo, madre
el futuro rey, se concibe en esta decoración con un lenguaje simbólico que mezcla elementos mitológicos
on emblemas y sofisticadas alegorías. Dentro del programa iconográfico de un palacio usado por la monar-
quía como lugar de ocio y representación del gusto y la sensibilidad artística de sus sucesivos moradores, aun
os espacios de privacidad mostraban un sistema de pensamiento costreñido por el más estricto decoro con-
Palabras clave: Pintura. Frescos. 1607. La Aurora. Monarquía.

If Felipe II in 1560 opted for a rich and sensual decoration for the private quarters of the El Pardo Palace, in 1607, after the 1604 fire, Felipe III approved a new program centered on the metaphor of the Catholic court adorned with all the theological and cardinal virtues. The intention of the decorative program of this vault appears to be explicit: the Spanish monarchy, personified by the Queen, mother of the heir, announces a new and happy dawn. The excellence of virtue as an attribute of the Queen - and above all, mother of the future king - is conceived in this decoration using a symbolic language in which mythological elements, emblems and sophisticated allegories are combined. Even within the iconographic program of a palace used by the Monarchy as a place of recreation, the private rooms demonstrated a system of thought controlled by the strictest Counter-Reformation decorum.

Key words: Painting. Frescos. 1607. Dawn. Monarchy.

Tan sólo cuatro piezas del Palacio del Pardo conservan las decoraciones frescadas y estucadas de gusto manierista ordenadas por los reyes Felipe II y Felipe III: el conocido techo de Becerra, en la torre de la Reina, con la fábula de Perseo (1562-1566); la Galería de la Reina, por Patricio Cajés, con la historia del bíblico José (1607); la antecámara de la Reina, por Jerónimo de Cabrera, narrando la historia de Esther (1613); y la cámara de la Reina, dedicada al tema de la Aurora (fig. 1), recientemente identificada como obra de Luis y Francisco de Car- 


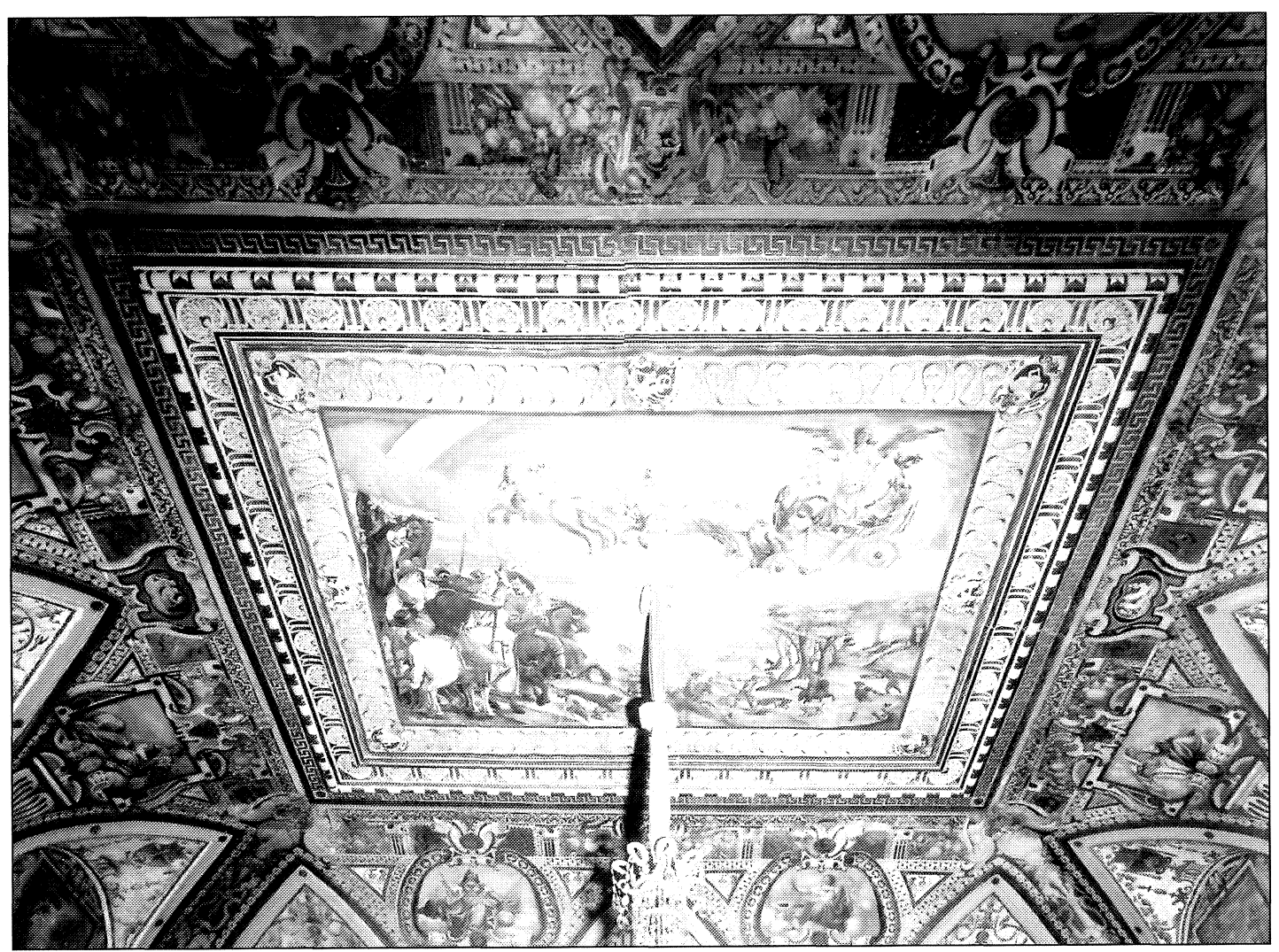

Fig. 1. Luis de Carvajal: La Aurora. El Pardo (Madrid): Palacio, bóveda de la Cámara de la Reina.

vajal $(1607)^{1}$. Todas ellas pertenecen a los que fueron aposentos de la Reina. En los antiguos aposentos del Rey, sólo una parte de la decoración del techo de la Sala de Retratos puede verse en la actualidad ${ }^{2}$.

De tamaño equivalente al techo de Becerra, el sistema desarrollado por Luis de Carvajal en la bóveda por él decorada presenta un esquema diferente. El tema principal: la diosa Aurora de pie sobre su carro tirado por cuatro caballos y una cacería, ocupa todo el espacio plano y aparece incluido en el techo, en un suntuoso marco formado por sucesivas molduras, como si fuera una pintura aplicada o «cuadro riportato», y separada del resto de la decoración por un pequeño espacio totalmente blanco. Alrededor de este cuadro, la zona abovedada se ha dividido en doce lunetos, con «cuadros» de paisajes en los semicírculos y grutescos de candelieri sobre ellos, mientras que los ocho espacios triangulares intermedios se decoran con cartelas enmarcando figuras femeninas sentadas portando diversos atributos. Sobre ellas, mascarones dorados y frutas con aves rodean el marco central. Pequeñas figuras de estuco fingido se distribuyen entre la moldura serliana de cinta en espiral, en cuatro medallones sobre los lunetos y en las cartelas doradas del vértice inferior de los triángulos.

\footnotetext{
1 Cfr. Araceli Martínez Martínez: «Un fresco del Palacio de El Pardo atribuido a Vicente Carducho, documentado como de Luis de Carvajal», en AEA, no. 254, Madrid, 1991.

2 María Kusche ha reconstruido con éxito la famosa Galería de Retratos de Felipe II, cfr. «La antigua Galería de Retratos del Pardo: su reconstrucción arquitectónica y el orden de colocación de los cuadros», en AEA, no. 253 , Madrid, 1991. Para la nueva Sala de Retratos de Felipe III cfr. Araceli Martínez Martínez: El Palacio de El Pardo. Historia y análisis de su construcción (1464-1630), tesis doctoral inédita. Universidad Autónoma de Madrid, 1991. También F. Marías: «El Palacio Real de El Pardo. De Carlos V a Felipe III», en RS, n." extraordinario, Madrid, 1989.
}

AEA, LXXV, 2002, 299, pp. 283 a 291 
La complejidad de la decoración, de brillantes colores y ricos dorados, está al servicio de una iconografía explícita y habitual en los palacios de los reyes, cuyas estancias suelen aparecer enriquecidas con pinturas en las que los temas mitológicos, heroicos y alegóricos pregonan la calidad de sus dueños, adornados por las virtudes simbolizadas en los programas desarrollados por pintores y escultores a la mayor gloria de sus moradores ${ }^{3}$.

Aquí, la Aurora aparece en su personificación alada, para indicar la rapidez de su movimiento, sosteniendo con su mano izquierda abundantes flores que esparce con la mano derecha. Corresponde esta imagen al texto de Ripa ${ }^{4}$. Va acompañada por el gallo, cuyo canto anuncia su llegada. Sobre el carro de la diosa una figura de anciano, flaco, con barba y cabellera blancas y grandes alas que expresan su rapidez, puede ser el tiempo y a su levedad alude, también, el reloj de arena junto a su costado izquierdo. El círculo del Zodíaco, con el signo de Scorpio visible, cierra la composición celeste. Una cacería ocupa la mitad inferior del cuadro, viéndose en primer término un grupo de nobles a caballo, el primero de los cuales, en corveta, figura la imagen ecuestre tan repetida en los cuadros de batallas del Salón de Reinos del Buen Retiro ${ }^{5}$.

Aunque ésta es la primera imagen que conocemos en España de la representación de la Reina como la Aurora, al parecer era tema favorito para la decoración de techos en palacios y casas señoriales ${ }^{6}$. La invocación de la esposa real como anunciadora de un nuevo día significaba el mensaje feliz atribuido a la bella diosa griega, mientras que la cacería hace alusión a la función del palacio y la actividad preferida por los monarcas, a la que se entregaban especialmente en su monte de El Pardo. El signo de Scorpio puede referirse al otoño especialmente propicio a la caza, en cuya estación se hallan como muestran los colores de las hojas.

De las ocho figuras femeninas que rodean el cuadro central, se identifica, en primer lugar, a la Monarquía en su personificación clásica como una matrona sedente y coronada, con aspecto grave y ataviada con armadura (fig. 2); sostiene el cetro con la mano diestra y posa la izquierda en la corona real. La bandera como símbolo de la victoria en la guerra de amor a la patria se agrupa con la corona y el globo terráqueo, viéndose los tres continentes por los que el Rey de España ha extendido sus dominios. La figura del ciervo, símbolo de la fecundidad ${ }^{7}$, junto al emblemático león, puede hacer referencia a la Reina como madre del futuro monarca.

Siguiendo la lectura en sentido contrario a las agujas del reloj, la segunda figura es una mujer que sostiene una balanza con la mano derecha y una espada con la izquierda (fig. 3). Tanto el aspecto grave como los atributos corresponden a la alegoría de la Justicia descrita por Ripa, si bien invirtiendo de mano los objetos. El jarro de agua o la palangana podrían querer dar a entender, según Alciato, la inocencia del juez que no recibió sobornos (Emblema XXXI). Sin embargo, la mirada penetrante dirigida hacia el mundo es propia de la Justicia Divina (Ripa).

Una joven bella y de aspecto modesto ocupa el tercer cuadro. Aparece revestida de un gran manto blanco que le cubre la cabeza. Sostiene una azucena con la mano derecha, mientras dirige los ojos hacia un libro (fig. 4). La azucena es símbolo de la pureza y atributo generalmente asociado a la Virgen María. Sin embargo, en este caso, es poco probable que la imagen representada personifique la virginidad; por la blancura de las ropas podría ser la Fe, que cuanto

${ }^{3}$ Cfr. Rosa López Torrijos: La mitología en la pintura española del Siglo de Oro. Madrid, 1985. Brown, J. y Elliott, J.H.: Un Palacio para el Rey. El Buen Retiro y la corte de Felipe IV. Madrid, 1981. Santiago Sebastián: Arte y Humanismo, Madrid, 1978. A. Herrera Casado: «El arte del humanismo mendocino en la Guadalajara del siglo Xvı», en Wad-al-Hayara, no. 8. Guadalajara, 1981 .

${ }^{4}$ C. Ripa: Iconografía. ed. de Santiago Sebastián, ed. Akal, Madrid, 1987, 2 vol.

${ }^{5}$ Cfr. Emblema XXV de Alciato. ed. de Santiago Sebastián, Madrid, 1985.

${ }^{6}$ Rosa López Torrijos, ob. cit., p. 154.

${ }^{7}$ Federico Revilla: Diccionario de Iconografía. ed. Cátedra, Madrid, 1990.

$A E A, \mathrm{LXXV}, 2002,299$, pp. 283 a 291 

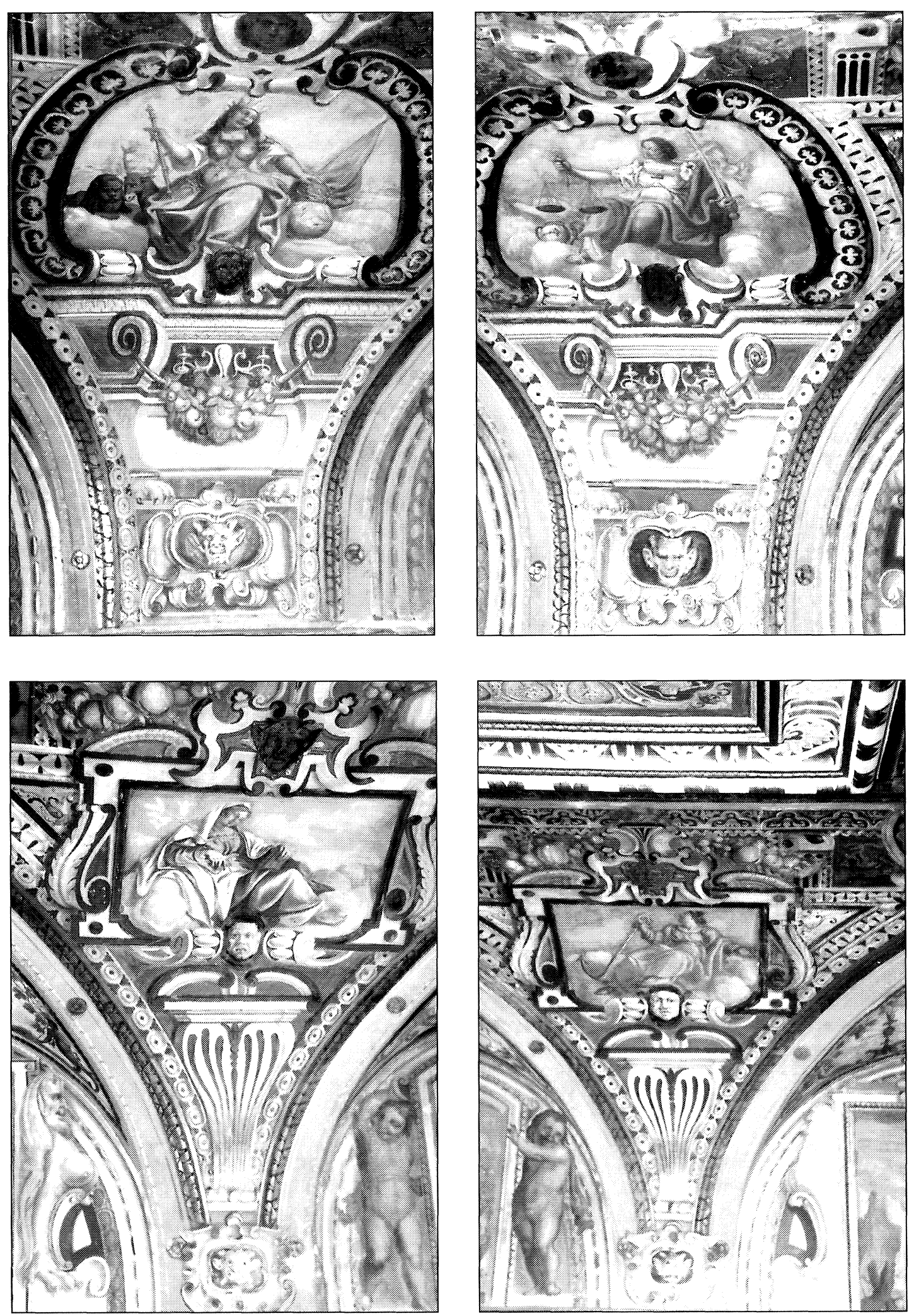

Figs. 2-5: Luis de Carvajal: El Pardo (Madrid), Palacio, bóveda de la Cámara de la Reina (detalles).

AEA, LXXV, 2002, 299, pp. 283 a 291 
más limpia y pura, más eficazmente actúa y logra su más alta perfección (Ripa). Que se trata de una alegoría de virtud teologal puede interpretarse por el libro, medio para adquirir y aprender la Santa Fe; para poseerla y mantenerla es preciso proteger el ingenio contra las armas enemigas: razonamientos naturales de los filósofos y las sofísticas alegaciones de los heréticos y los malos cristianos. Otra posible explicación para la inclusión de la azucena cabe inferirla del significado de la Fe recogido por Alciato como símbolo de la Fidelidad, por lo que la Reina estaría adornada de la virtud de la Fidelidad.

La cuarta figura es una joven ataviada con un gran manto verde, apoyada su mano derecha en un ancla, mientras eleva la mirada a lo alto y abre su mano izquierda en señal de súplica (fig. 5). Según Ripa los ojos dirigidos a lo alto son signo de la Esperanza Divina, ya que Dios es el verdadero fundamento de las humanas esperanzas. El color verde simboliza el tono de los campos en la primavera, como presagio de los frutos del estío y el otoño. El ancla representa la seguridad; en este caso, muestra que la esperanza que el mundo tiene en Su Magestad es cierta y firme. También Alciato representa sus emblemas dedicados a ilustrar la virtud de la Esperanza con los símbolos que vemos en esta figura: los ojos dirigidos al cielo, verdes vestiduras y el áncora (Emblemas XLIV y CXLIII). Con un ancla aparece representada la Esperanza en uno de los tres arcos triunfales erigidos por la villa de Madrid para la entrada de la reina Margarita de Austria el 24 de octubre de 1599, en el que intervino Luis de Carvajal ${ }^{8}$.

Vestida con un manto encarnado, la Caridad aparece representada con sus atributos tradicionales: un niño entre sus brazos y otros dos cobijados bajo su manto o en su regazo (fig. 6), significando que la caridad es un afecto puro y ardiente del ánimo que se orienta hacia Dios y hacia sus criaturas. Los tres chiquillos muestran cómo, si bien la caridad es una sola virtud, posee un triple poder, pues sin ella nada importan la fe ni la esperanza (Ripa).

Junto a la Caridad, se ve la imagen de la Fortaleza, personificada en una joven ataviada con ropas de guerrero: casco y armadura, abrazada a una columna (fig. 7). A su derecha, aparece un león, significando que todo hombre que quiera basar su honor y nombradía en la virtud de la Fortaleza ha de comportarse, en la realización de sus actos y empresas, como el león, animal valeroso que siempre se expone a lo más grande y arriesgado, aborreciendo con ánimo desdeñoso las cosas bajas y viles, hasta el punto que rehúsa ejercitar sus grandes fuerzas con quien en principio le resulte inferior de manera evidente (Ripa). La columna representa la fortaleza de ánimo y es un atributo que no recogen Ripa ni Alciato en su sistematización de los signos iconográficos; posiblemente, sea un elemento tomado de la Biblia, aludiendo a Sansón, o de las Metamorfosis, referido a Hércules.

La siguiente figura, con dos vasos entre sus manos, vierte parte del contenido de uno en otro, representación de la Templanza (fig. 8), según el texto de Ripa, quien define esta virtud como una especie de equilibrada mesura, guiada y determinada por un certero raciocinio, en todo cuanto respecta a los placeres o displaceres del cuerpo, tal como lo percibimos a través de los sentidos, con el tacto y el gusto, actuando de acuerdo a lo que es conveniente por amor de lo honesto y lo más útil. La mezcla de líquidos, frío y caliente, en uno solo, significa la moderación conseguida cuando se armonizan distintos extremos.

Una figura de mujer joven mirándose en un espejo, que sostiene con la mano derecha, y una serpiente en la izquierda, representa la Prudencia (fig. 9). Aparece con los atributos tradicionales de esta virtud, sistematizados por Ripa. Ya en el Evangelio se dice: «Sed prudentes como la serpiente» que, cuando se ve combatida, opone todas las fuerzas de su cuerpo al ata-

${ }^{8}$ Cfr. V. Tovar Martín: «La entrada triunfal en Madrid de doña Margarita de Austria (24 de octubre de 1599)», en AEA, no. 244, Madrid, 1988, p. 385 y ss. El contrato transcrito en Trinidad de Antonio: Pintura española del último tercio del siglo XVI en Madrid: Juan Fernández de Navarrete, Luis de Carvajal y Diego de Urbina, tesis doctoral inédita, Universidad Complutense de Madrid, 1987. Doc. 21. 

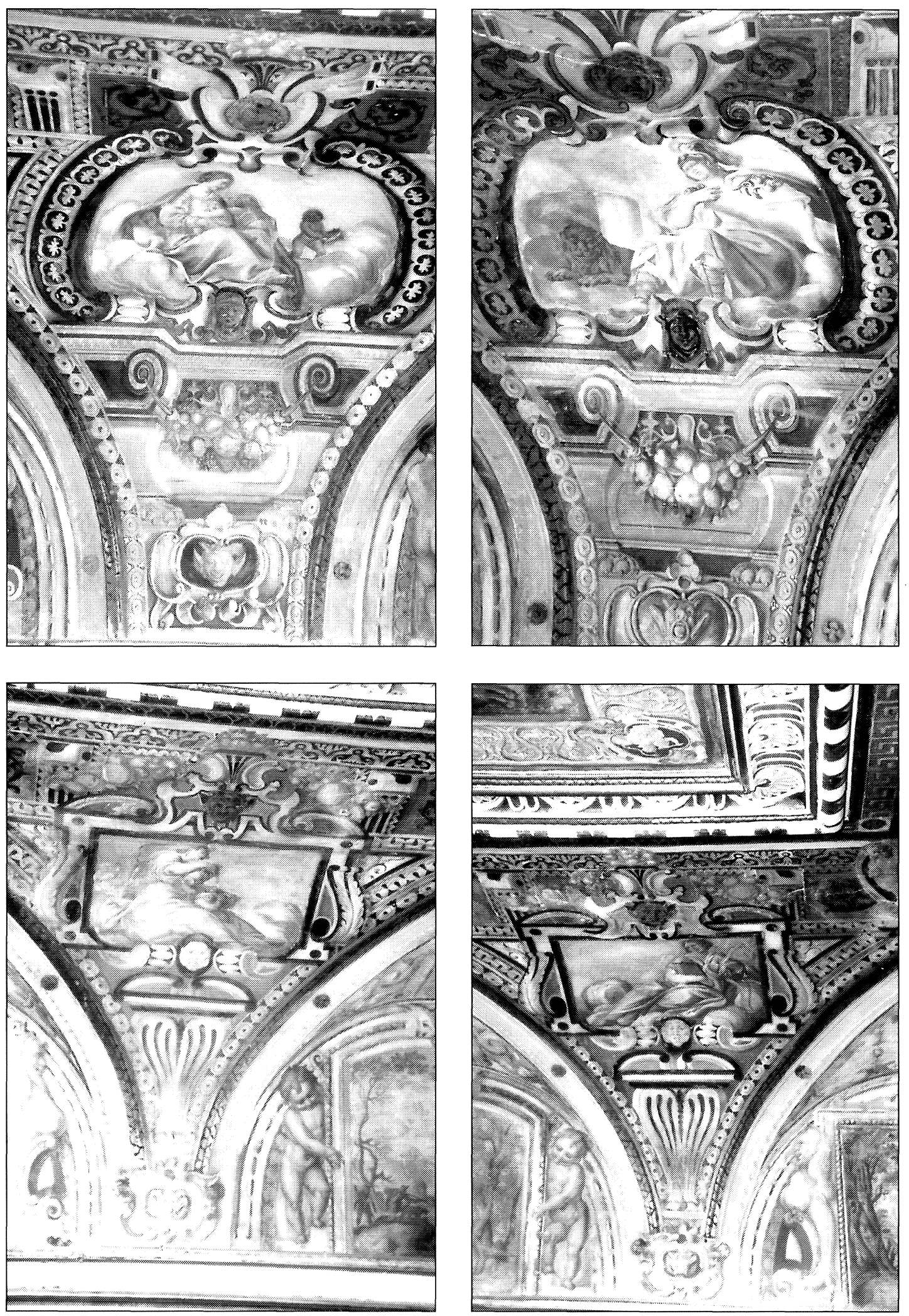

Figs. 6-9. Luis de Carvajal: El Pardo (Madrid), Palacio, bóveda de la Cámara de la Reina (detalles).

AEA, LXXV, 2002, 299, pp. 283 a 291 
que que recibe, irguiendo la cabeza y amagando con ella mientras se envuelve en sus anillos, simbolizándose con esto que por defender nuestra virtud y perfección, que vienen a equivaler a la cabeza, deberemos oponer a los golpes de fortuna la totalidad de nuestras fuerzas y recursos. El espejo simboliza el modo de cognición que utiliza el prudente, no siéndonos posible regular nuestras acciones sin el perfecto y adecuado conocimiento y corrección de los defectos que tuviéremos. Lo mismo advertía Sócrates cuando exhortaba a sus discípulos a mirarse en el espejo todas las mañanas.

La intención del programa decorativo de esta bóveda parece explícita: la Monarquía española, personificada en la Reina, madre del heredero, que anuncia un amanecer nuevo y feliz, se presenta adornada de todas las virtudes, teologales y cardinales.

Esta simbología aparece reforzada por las aves, que se posan o picotean los frutos. Así, la lechuza (fig. 10) se habría incluido como símbolo de la prudencia y la sabiduría ${ }^{9}$.

Las guirnaldas de frutos que aparecen a los pies de algunas figuras son signo de fertilidad. La inclusión del tema de frutos en las decoraciones de techos palaciegos renacentistas tiene, en España, un antecendente de mano italiana en los «cuartos nuevos» de la Alhambra ${ }^{10}$. De parecido tipo son los grupos de frutos y aves del techo de la Galería del Prelado del Palacio Arzobispal de Sevilla, atribuidos al discípulo de Pablo de Céspedes, Antonio Mohedano (15611626), y realizados en la misma fecha que la bóveda del Palacio de El Pardo ${ }^{11}$.

Las escenas «estampadas» de Hércules dando muerte con la maza al león de Nemea (fig. 11), uno de los Doce Trabajos a que fue condenado para expiar su crimen, podrían hacer alusión a las pruebas que debe pasar el alma hasta liberarse de la servidumbre del cuerpo, así como de las pasiones ${ }^{12}$. Aunque debe señalarse que tanto en el Renacimiento como en el Barroco hispano la figura del héroe mítico aparece asociada a la monarquía española, incluso como fundador de la dinastía ${ }^{13}$. Otras figuras monstruosas podrían significar los vicios... No obstante, todos los seres negativos: monstruos marinos, genios, harpías, etc. se pintan fingiendo estucos por lo que su significado sería muy secundario, quizá sólo decorativo y no emblemático.

De los doce «cuadros» de paisajes figurados en los semicírculos de las lunetas, los cuatro que ocupan el centro de cada lado aparecen sostenidos por parejas de «putti» (fig. 12), presentando remate curvo y dos pequeñas ménsulas doradas en los ángulos superiores, mientras que los ocho restantes se flanquean por harpías de estuco fingido. Aunque las figuras de estos cuadros (cazadores a pie o a caballo con sus perros y las posibles presas, y pescadores con sus cañas) añadan una imagen de verosimilitud y cotidianeidad a los paisajes, creo que son imaginarios. En efecto, las ruinas clásicas de alguno, los árboles fantásticos de otro (fig. 13) o las arquitecturas narrativas a modo de castillo al fondo de una creíble escena de caza (fig. 12), no pueden relacionarse con los paisajes visibles en el monte del Pardo. Por el número: doce, podría pensarse en la habitual representación de los Doce meses del año, tema que puede verse en el mismo Palacio de El Pardo en la cámara contigua a la que estamos estudiando, decorada por el pintor madrileño Jerónimo de Cabrera después de $1613^{14}$. Resulta problemática esta lectura de los paisajes de Luis de Carvajal, sobre todo porque algunos presentan graves deficiencias de conservación que nos impiden interpretar los colores y las luces haciendo alusión a la altura del sol según los distintos meses. No obstante, es posible que en el programa original se incluyera este motivo.

\footnotetext{
9 James Hall: Diccionario de temas y símbolos artísticos, ed. Alianza. Madrid, 1987.

${ }^{10}$ Cfr. Rosa López Torrijos: «La escuela de Rafael y el bodegón español», en AEA, no. 233, Madrid, 1986 , pp. 33-52.

$"$ Cfr. nota anterior y tb. Pérez Sánchez, A.E.: La Nature Morte espagnole du XVIIe siècle à Goya, Fribourg, 1987.

12 Cfr. Santiago Sebastián, 1978, ob. cit.

${ }_{13}$ Cfr. nota 3 .

${ }^{14}$ Cfr. Angulo, D. y Pérez Sánchez, A.E.: Pintura madrileña. Primer tercio del siglo XVII. Madrid, 1969.
} 

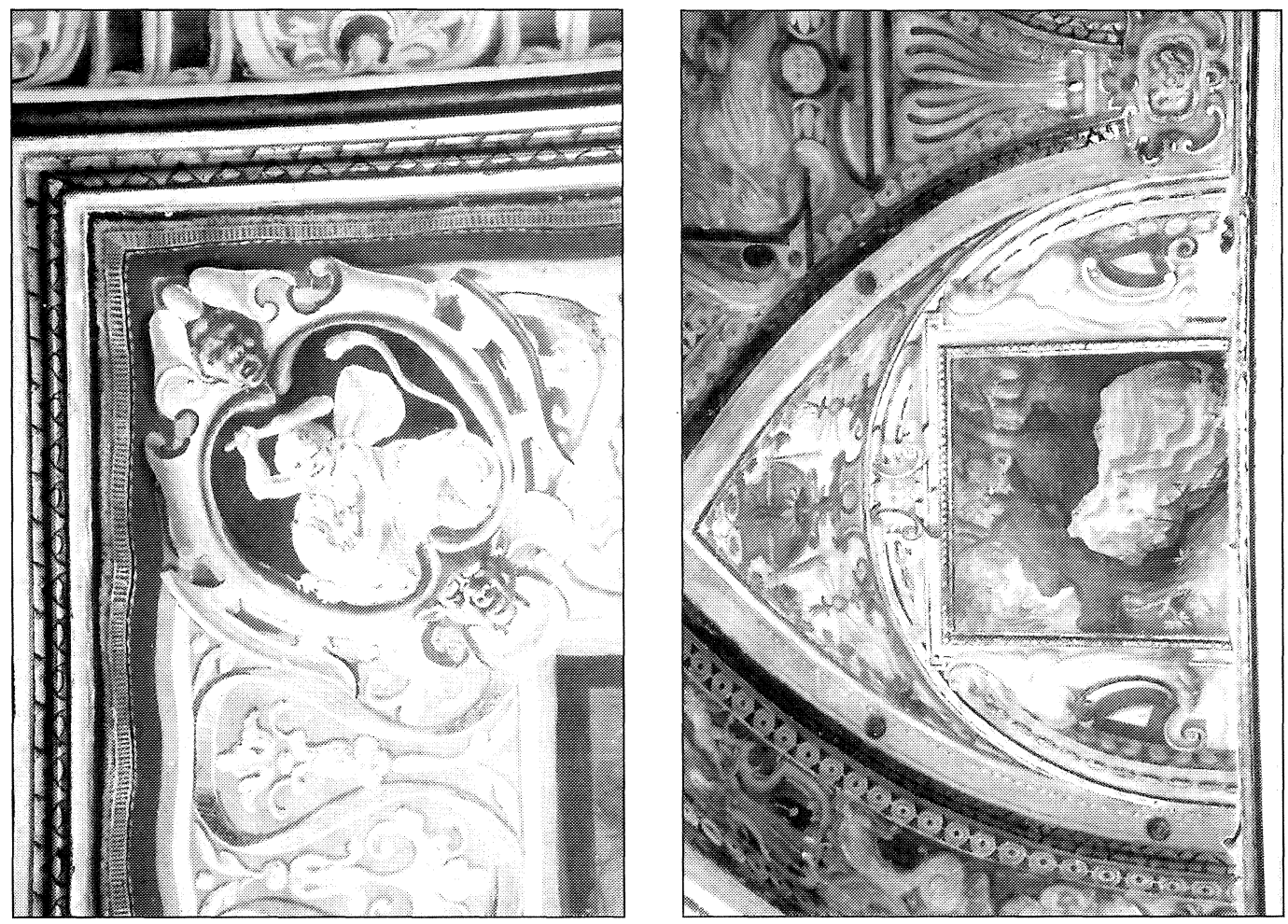

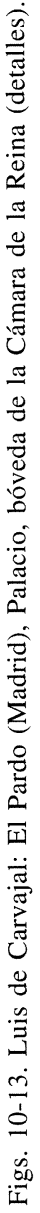
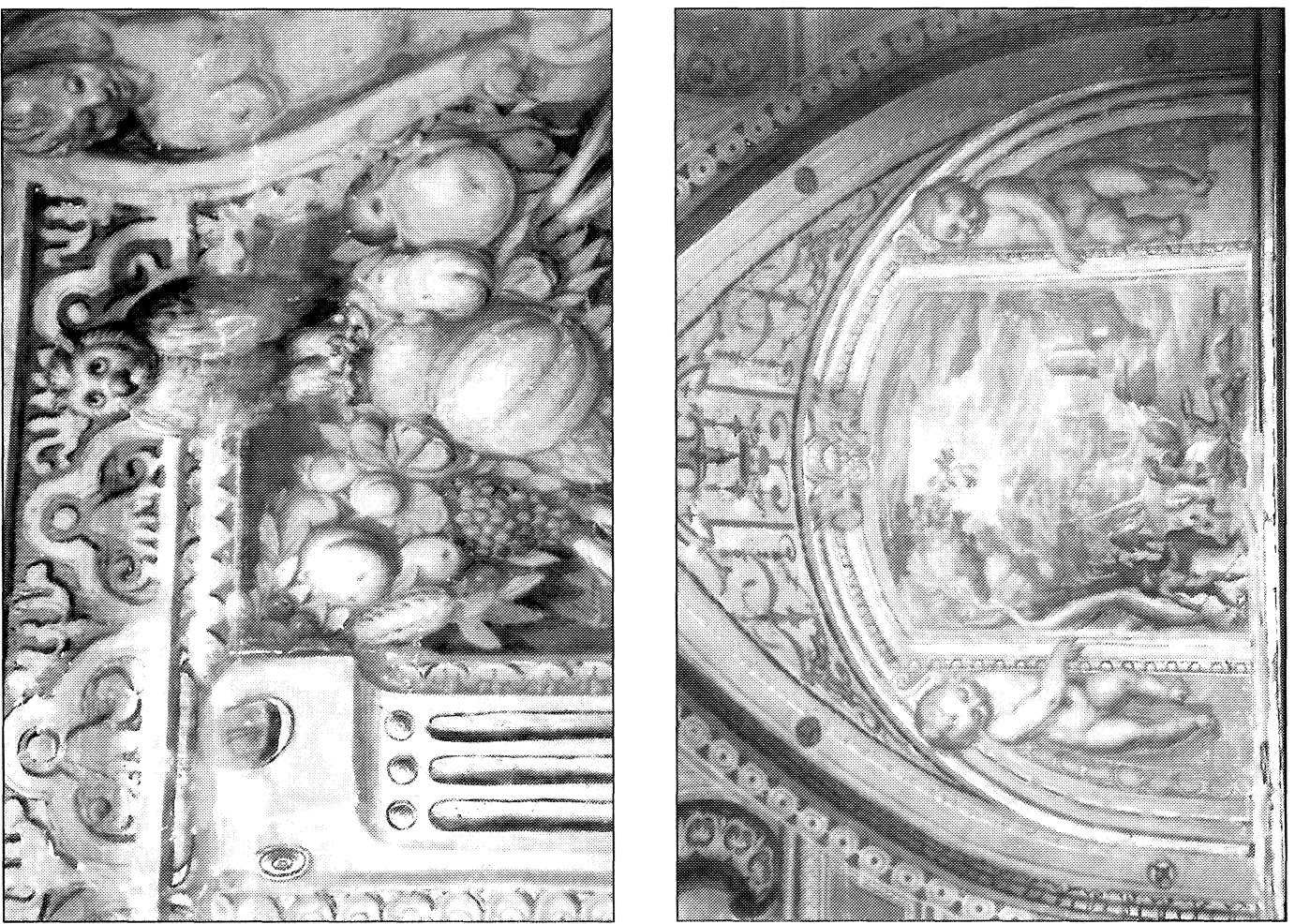

AEA, LXXV, 2002, 299, pp. 283 a 291 
Luis de Carvajal demuestra, en esta obra, conocer no sólo la técnica del fresco (que aprendería en Italia, durante su estancia, documentada en 1577, a los 21 años), sino todos los saberes exigidos a los artistas considerados como inventores ingeniosos, calificación sólo merecida por los que dominaban todas las ramas de la técnica, el dibujo y la pintura. Además, serían eruditos conocedores de la Biblia, la mitología, heráldica, emblemas, jeroglíficos, etc. Suya sería la traza de esta compleja decoración, como se deduce del relato de Vicente Carducho: «otra quadra estuvo a cargo de Luis de Carvajal» ${ }^{15}$, y se confirma por los datos suministrados por el inventario de sus bienes ${ }^{16}$. De los veinticinco libros —unos en italiano y otros en castellano-que poseía desconocemos sus títulos, pero serían los habituales de un pintor de su época y formación en la Roma de 1577 y en El Escorial de las siguientes décadas.

Más información proporciona la relación de sus pinturas, dibujos y grabados. Nos consta que siguió la costumbre italiana de realizar dibujos preliminares para cada composición y para los detalles individuales. Abundan los dibujos de su mano, más de ciento cuarenta y cuatro, de los que conocemos dos de gran finura ${ }^{17}$. Su dominio de la técnica del dibujo y su categoría de pintor ingenioso le acreditarían para contratar, junto con Pompeyo Leoni y Bartolomé Carducho, los tres arcos triunfales para la entrada en Madrid de la reina Margarita de Austria, en $1599^{18}$. Para estas composiciones se daba a los artistas las medidas y la traza general con la estructura arquitectónica, pero tanto las figuras de bulto entero como las pinturas de los cuadros serían «las que parezerá mejor al poeta que hiziere el alma del y deste dicho arco», según se lee en el contrato.

De su interés por el mundo clásico romano y los planteamientos que sobre frescos decorativos hallaría en Roma y en El Escorial, son muestra algunos de los objetos de su taller, como cinco estampas de diosas, una cabeza de yeso de «la noche» de Miguel Ángel, cinco estampas de los trabajos de Hércules, catorce estampas de los planetas y Hércules, estampas de anatomía de Durero, junto a otras de paisajes y animales en general.

Sobre todo, comprobamos que Luis de Carvajal tuvo oportunidad de poner en práctica los conocimientos teóricos y prácticos aprendidos en su estancia romana, ya que participó en tres programas decorativos de gran alcance, al servicio de la monarquía: El Escorial, con temas religiosos; las decoraciones de los arcos levantados en Madrid para el recibimiento de la Reina Margarita de Austria, con temas alegóricos e históricos, y la mayor empresa artística del reinado de Felipe III: la decoración de los techos y bóvedas del Palacio de El Pardo -perdidos en el incendio de 1604- con temas mitológicos y alegóricos, junto a elementos de gran fantasía. Aquí nos dejó una obra de sorprendente complejidad compositiva, demostrando maestría en la composición de naturalezas muertas y gran erudición para ilustrar conceptos con imágenes, tal como se venía haciendo en Italia desde los comienzos del Manierismo.

\footnotetext{
${ }^{15}$ Vicente Carducho: Diálogos de la pintura, Madrid, 1933. ed. de F. Calvo Serraller, Madrid, 1979.

${ }^{16}$ Cfr. Barrio Moya, J.L.: «El pintor Luis de Carvajal y el inventario de sus bienes», en BSAAV, Valladolid, 1982, pp. 414-420. Trinidad de Antonio, 1987, ob. cit.

${ }^{17}$ Angulo, D. y Pérez Sánchez, A.E.: A Corpus of Spanish Drawings, I: 1400-1600. Londres, 1975. Pérez Sánchez, A.E.: Historia del dibujo en España. De la Edad Media a Goya. Madrid, 1986.

${ }^{18} \mathrm{Cfr}$. nota 8.
} 